\title{
Electrical properties of reduced 3YTZP ceramics consolidated by spark plasma sintering
}

R. Poyato ${ }^{1}$, J. Macías-Delgado ${ }^{1,2}$, A. García-Valenzuela ${ }^{1,2}$, R. L. González-Romero ${ }^{2}$, A. Muñoz ${ }^{2}$, A. Domínguez-Rodríguez ${ }^{2}$

1. Instituto de Ciencia de Materiales de Sevilla (CSIC-Univ. Sevilla), Avda. Américo Vespucio 49, 41092 Sevilla, Spain.

2. Departamento de Física de la Materia Condensada, Univ. de Sevilla, Apdo. 1065, 41080 Sevilla, Spain.

\begin{abstract}
$3 \mathrm{~mol} \%$ yttria doped zirconia ceramics were consolidated by spark plasma sintering (SPS) at two sintering temperatures with the aim of achieving two different reduction levels. Microstructural characterization of the ceramics was performed by scanning electron microscopy (SEM). Electrical properties were investigated by means of impedance spectroscopy from room temperature up to $500^{\circ} \mathrm{C}$. The two ceramics presented a remarkably different electrical behaviour. The effect of the extra electrons introduced by reduction during SPS on both the bulk and the grain boundary conductivity was analysed and discussed.
\end{abstract}

Keywords: Zirconia; Spark plasma sintering; Impedance spectroscopy; Electrical conductivity

*Corresponding author. E-mail address: rosalia.poyato@icmse.csic.es

Phone number: +34954 489534

FAX number: +34954460665 


\section{Introduction}

In the last decade, several works have been devoted to the study of the conductivity of yttria-doped zirconia, ${ }^{1-12}$ as the high ionic conductivity and stability of this ceramic make it a technologically interesting material for a wide range of applications such as solid oxide fuel cell or oxygen sensor. ${ }^{13-16}$

It is well known that considerable amount of electrons can be introduced to zirconia ceramics under reducing conditions, however, although much research has been focused on the high ionic conductivity due to oxygen vacancies, the studies regarding the electric performance in reduced zirconia are scarce. ${ }^{17-23}$ Levy et al. ${ }^{17}$ studied electrical conductivity of electrochemically reduced samples of 9 and $12 \mathrm{~mol} \% \mathrm{Y}_{2} \mathrm{O}_{3}$ stabilized zirconia and reported a significant effect of the electronic conductivity in highly reduced ceramics, with higher total conductivity at temperatures from 120 to 500 ${ }^{\circ} \mathrm{C}$, when comparing with ceramics with a low deviation from oxygen stoichiometry. These authors proposed a model for the electrical conductivity with two different conduction processes, ionic and electronic, depending on the deviation from stoichiometry. When the quantity of injected electrons is small, they remain localized on deep traps and no electronic conductivity contribution is observed. On the other hand, for highly reduced ceramics the number of electrons is higher than the number of deep traps and they remain in a sort of conduction band.

A comprehensive study on the electron traps present in thermochemically reduced $16 \mathrm{~mol} \% \mathrm{Y}_{2} \mathrm{O}_{3}$ zirconia single crystals was carried out by Merino et al. ${ }^{18}$ They described the presence of two different electron traps, C-and T-defects, and their correlation with total electrical conductivity. Whereas at low reduction levels only the 
most stable T-defects are produced and the total conductivity is not affected, a two orders of magnitude increase in conductivity is observed in highly reduced materials when C-defects are present.

The remarkable effect of electronic contribution on total conductivity at relatively low temperatures was also found by Sano et al. ${ }^{19}$ for electrochemically reduced $3 \mathrm{~mol} \% \mathrm{Y}_{2} \mathrm{O}_{3}$ doped zirconia. However, in these studies ${ }^{17-19}$ the effect of the injected electrons on the bulk and grain boundary conductivities was not analysed.

More recently, Guo and Ding ${ }^{20}$ studied the effect on electrical conductivity from 325 to $550{ }^{\circ} \mathrm{C}$ of introducing a high density of electrons by codoping the zirconia with 8 mol\% $\mathrm{TiO}_{2}$ and $7.36 \mathrm{~mol} \% \mathrm{Y}_{2} \mathrm{O}_{3}$. When dissolved, $\mathrm{Ti}^{4+}$ substitutionally replaces $\mathrm{Zr}^{4+}$ in the $\mathrm{ZrO}_{2}$ fluorite lattice without changing the original crystal structure and, after annealing at low oxygen partial pressure $\left(2 \% \mathrm{H}_{2}-\mathrm{Ar}\right.$ mixture $)$, titanium ions, $\mathrm{Ti}^{4+}$, are reduced to $\mathrm{Ti}^{3+}$ to give electrons that remain mostly in the structure. They demonstrated the simultaneous increase of electronic partial conductivity and total conductivity both in the bulk and at the grain boundaries, with a more drastic increase for the grain boundaries due to the electron accumulation in the space charge layers. A change in the overall grain boundary conduction from pure ionic to mixed ionic-electronic due to segregation of electrons to the space charge zone, while maintaining the pure ionic conductivity in the bulk, was reported by Lee et al. ${ }^{21}$ for 2.44 mol\% $\mathrm{Y}_{2} \mathrm{O}_{3}$ doped $\mathrm{ZrO}_{2}$. In this study, the excess electrons were introduced by reducing the sample during spark plasma sintering (SPS), as in this technique the samples are sintered in a vacuum inside a carbon die. However, the sintering conditions were not specified in the study and the conductivity analysis was carried out in a relatively narrow temperature range (180-300 $\left.{ }^{\circ} \mathrm{C}\right)$. 
In the present work, $3 \mathrm{~mol} \% \mathrm{Y}_{2} \mathrm{O}_{3}-\mathrm{ZrO}_{2}$ ceramics were spark plasma sintered at two different temperatures, 1250 and $1300{ }^{\circ} \mathrm{C}$, with the aim of achieving different reduction levels. The as-sintered ceramics were also thermally treated in order to establish a comparison with a purely ionic conducting zirconia. Microstructure and phases of the materials were characterized, as well as the electrical properties by impedance spectroscopy from room temperature up to $500^{\circ} \mathrm{C}$. The effect of the extra electrons introduced by reduction during SPS on both the bulk and the grain boundary conductivity was analysed and discussed.

\section{Experimental}

$3 \mathrm{~mol} \%$ yttria stabilized tetragonal zirconia powder (3YTZP), with $40 \mathrm{~nm}$ particle size and $99 \%$ purity, was obtained from a commercial source (Nanostructured and Amorphous Materials Inc., Houston, Texas). Spark plasma sintering (Model 515S, Dr Sinter Inc., Kanagawa, Japan) of the powders was performed in vacuum in a $15 \mathrm{~mm}$ diameter cylindrical graphite die/punch setup, under a uniaxial pressure of $75 \mathrm{MPa}$ at 1250 or $1300{ }^{\circ} \mathrm{C}$ for $5 \mathrm{~min}$ (ceramics hereinafter called 3YTZP-1250 and 3YTZP-1300). A sheet of graphite paper was placed between the powders and die/punches for easy specimen removal. Temperature was measured by means of an optical pyrometer focused on a bore hole in the middle part of the graphite die. The sintered ceramics of $\sim 15 \mathrm{~mm}$ in diameter and $\sim 2 \mathrm{~mm}$ in thickness were ground to eliminate the surface carbon. A marked black colour on the sintered samples was observed after SPS densification. However, when these samples were subsequently annealed in air at 1000 ${ }^{\circ} \mathrm{C}$ for $1 \mathrm{~h}$, their colour changed back to white. Thus, colour change during SPS is the consequence of oxygen nonstoichiometry, as also reported by previous authors. ${ }^{5,18}$ 
Density of the ceramics was determined using the Archimedes' method, using water as the immersion liquid.

Microstructural observations of sintered ceramics were carried out on polished surfaces by high-resolution scanning electron microscopy (HRSEM), using a Hitachi S5200 microscope (Hitachi High Technologies America Inc., USA). Polished samples (up to $1 \mu \mathrm{m}$ diamond paste) were thermally etched in air for $20 \mathrm{~min}$ at a temperature $100{ }^{\circ} \mathrm{C}$ below the sintering temperature, to reveal the grain boundaries. The morphological characterization was made measuring about 200 grains to obtain the equivalent planar diameter as size parameter, $d=2(\operatorname{area} / \pi)^{1 / 2}$, and the shape factor, $f$ $=(4 \pi \cdot$ area $) /(\text { perimeter })^{2}$.

Raman spectra were recorded on polished surfaces using a dispersive microscope (Horiba Jobin Yvon LabRam HR800, Kyoto, Japan), with a $20 \mathrm{~mW}$ He-Ne green laser $(532.14 \mathrm{~nm})$, without filter, and with a 600 lines per mm grating. The microscope used a 100x objective and a confocal pinhole of $100 \mu \mathrm{m}$. The Raman spectrometer was calibrated using a silicon wafer. Raman studies were carried out for as-sintered samples as well as for thermally treated ceramics with the aim of establishing possible variations in the structure.

Electrical characterization was carried out by Impedance Spectroscopy in the frequency range of 100 to $2 \times 10^{6} \mathrm{~Hz}$ using an Agilent 4294A impedance analyzer from 25 to $500{ }^{\circ} \mathrm{C}$. Measurements were carried out in Ar atmosphere to avoid possible oxidation of the samples during the process. Impedance data were obtained in the assintered ceramics and also in the thermally treated ones. For the measurements, silver paste was applied on both sides of the samples, and electrodes were fired at $600{ }^{\circ} \mathrm{C}$ for 
30 min, under Ar flow to avoid oxidation of the samples. Equivalent circuit approach was adopted for the data analysis with fitted curve using Z-view software and equivalent circuit model.

\section{Results and discussion}

\subsection{Microstructural characterization.}

Figure 1 shows the HRSEM micrographs of thermally etched polished surfaces and grain size distribution plots of the ceramics sintered at 1300 and $1250{ }^{\circ} \mathrm{C}$. The relative density values and morphological parameters (mean grain size, standard deviation and shape factor) of the sintered ceramics are shown in Table 1.

An increase in relative density $\left(\rho_{\mathrm{r}}\right)$ and grain size $(\mathrm{d})$ is observed when increasing the sintering temperature. An equiaxed grain microstructure was found in both materials (shape factor around 0.7). Finer grain size with narrower size distribution (smaller $\sigma_{\mathrm{d}}$ ) was found in the ceramic sintered at $1250^{\circ} \mathrm{C}$, but differences in relation to the grain shape were not appreciated (Table 1).

Raman spectra measured in the as-sintered, as well as in the thermally treated, ceramics are presented in Figure 2. The spectra show peaks centred at 165, 265, 320, 465,612 and $643 \mathrm{~cm}^{-1}$ demonstrating the tetragonal phase of the $3 \mathrm{YTZ}$, as these peaks correspond to the six Raman bands theoretically predicted for tetragonal zirconia. ${ }^{24,25}$ The light shoulder appreciated at $480 \mathrm{~cm}^{-1}$, approximately, for all the ceramics can be assigned to the presence of a small trace of monoclinic phase in the ceramics. ${ }^{25}$ No noticeable changes are observed in the peaks position in the spectra corresponding to thermally treated ceramics, suggesting structural stability in the sintered materials. 


\subsection{Electrical characterization.}

Figure 3 shows the impedance data obtained in the ceramic sintered at $1300^{\circ} \mathrm{C}$, from room temperature up to $210^{\circ} \mathrm{C}$. The impedance complex plane plots, Figure 3(a), show a single semicircular arc until temperature reaches $\sim 200{ }^{\circ} \mathrm{C}$, when a second arc is observed at low frequencies. The Z" spectra, Figure 3(b), show a single peak until this temperature, when a second peak at low frequencies is observed. No impedance data could be acquired in the ceramic after thermal treatment for temperatures lower than $\sim 200^{\circ} \mathrm{C}$. In the case of the ceramic sintered at $1250^{\circ} \mathrm{C}$ impedance data could not be acquired for temperatures lower than $\sim 200{ }^{\circ} \mathrm{C}$ neither in the as-sintered ceramic nor in the thermally treated one. Thus, electrical conductivity from room temperature up to $200{ }^{\circ} \mathrm{C}$ was only measured in the as-sintered ceramic when SPSed at $1300{ }^{\circ} \mathrm{C}$.

Typical impedance spectra measured at $300{ }^{\circ} \mathrm{C}$ in the as-sintered and thermally treated 3YTZP-1300 and 3YTZP-1250 ceramics are shown in figure 4. In both cases it is observed an increase of the impedance spectra (and thus, of the total resistivity of the ceramic) after the thermal treatment; however, the increase is more remarkable in the ceramic sintered at $1300{ }^{\circ} \mathrm{C}$, with a significant effect on the arc at low frequencies.

The obtained spectra were fitted to an equivalent circuit composed by one RCPE (constant phase element in parallel with a resistance) in the case of spectra with a single arc, or two R-CPEs connected in series, in the case of spectra with two arcs. Typically, in ionic conductors the arc at higher frequencies (with associated capacitance values in the order of $10^{-12}-10^{-11} \mathrm{~F}$ ) is ascribed to the ionic conductivity through the bulk, while the arc at lower frequencies (with associated capacitance values in the order 
of $10^{-11}$ and $10^{-8} \mathrm{~F}$ ) is related to the ionic conductivity through the grain boundary.

However, in this study, the ceramic sintered at $1300^{\circ} \mathrm{C}$ presents conductivity from room temperature to $200^{\circ} \mathrm{C}$, showing a single arc in the complex plane. Fitting of these arcs gave an associated capacitance with values in the order of $10^{-12} \mathrm{~F}$. It is clear that this arc corresponds to electronic conduction through the bulk at temperatures from room temperature up to $200{ }^{\circ} \mathrm{C}$. For higher temperatures, when ionic conductivity begins to be noticeable, both ionic and electronic conduction contribute to the conductivity and the arc at higher frequency would contain both mechanisms. In the same way, the arc at lower frequency would describe both ionic and electronic conductivity through the grain boundary.

The Arrhenius plots of the bulk and the specific grain boundary conductivities for the $3 \mathrm{YTZP}-1250$ ceramic (as-sintered and after thermal treatment) are presented in figure 5 . The specific grain boundary conductivity was calculated considering the brick layer model and assuming the dielectric permittivity of grain boundary and bulk are $\operatorname{similar}\left(\varepsilon_{\mathrm{GB}} \approx \varepsilon_{\text {bulk }}\right)$, by using the equation:

$$
\sigma_{G B}=\frac{R_{B u l k} * C_{B u l k}}{R_{G B} * C_{G B}} \sigma_{B u l k}
$$

with $R$ and $C$ being resistance and capacitance, respectively, obtained by fitting the impedance spectra. The bulk resistivity was calculated using the equation:

$$
\sigma_{E u l k}=\frac{A}{L} R_{B u l k}
$$

where $A$ and $L$ are the electrode area and the sample thickness, respectively. 
Similar activation energies (Table 2) were obtained for the ceramic before and after thermal treatment. The activation energies are slightly lower but in reasonable agreement with values previously reported in the literature for 3YTZP ceramics $\left(\mathrm{Ea}_{\mathrm{Bulk}}=0.92-0.99 \mathrm{eV}, \mathrm{Ea}_{\mathrm{GB}}=1.06-1.09 \mathrm{eV}\right)$ sintered in conventional furnace ${ }^{2,9}$ or by SPS $^{7}$. However, although similar bulk conductivity values were obtained in the whole temperature range before and after the thermal treatment, slightly higher grain boundary conductivities were obtained in the ceramic before the thermal treatment. These results are similar than the previously reported ones ${ }^{17,18}$ regarding zirconia at low reduction levels. In this case, the ceramic sintered at $1250^{\circ} \mathrm{C}$ probably presents a low deviation from stoichiometry and only the most stable T-defects are produced. ${ }^{18}$ The introduced electrons remain mostly localized in these deep traps, resulting in purely ionic bulk conductivity and mixed ionic-electronic grain boundary conductivity, as reported previously $^{21}$ for 2.44 mol\% doped zirconia.

The Arrhenius plots of the bulk and the specific grain boundary conductivities for the 3 YTZP-1300 ceramic (as-sintered and after thermal treatment) are presented in figure 6. For the as-sintered 3YTZP-1300 ceramic, the Arrhenius curve for the bulk conductivity presents clearly two different slopes for low and high temperature ranges. For temperatures up to $\sim 200^{\circ} \mathrm{C}$, very low activation energy $(0.20 \mathrm{eV})$ is obtained. For intermediate temperatures, between 200 and $300{ }^{\circ} \mathrm{C}$, the curve shows an increasing slope with temperature. At higher temperatures, the activation energy is the same as the obtained one after the thermal treatment (Table 2). This behaviour is similar to the reported ones by Levy et al. ${ }^{17}$ and Sano et al. ${ }^{19}$ for the total conductivity of highly reduced $12 \mathrm{~mol} \% \mathrm{Y}_{2} \mathrm{O}_{3}$ doped $\mathrm{ZrO}_{2}$ and $3 \mathrm{~mol} \% \mathrm{Y}_{2} \mathrm{O}_{3}$ doped $\mathrm{ZrO}_{2}$ ceramics, respectively. 
In the present study, it is clear that the low activation energy for $\mathrm{T}<200{ }^{\circ} \mathrm{C}$ is due to the electronic conduction through the bulk caused by the extra electrons introduced by reduction of the sample during SPS. The activation energy is very low, corresponding only to that of the electron mobility. ${ }^{17}$ This conduction is associated to the presence of C-defects produced in strongly reduced zirconia. The number of injected electrons is therefore significantly greater than the number of deep traps (T-defects) and the shallower C-defects determine the low temperature electronic conductivity of the material. ${ }^{18}$ To the best of our knowledge, this is the first time that such a strong effect of the extra electrons on the bulk conductivity, promoting even the existence of conductivity at room temperature, is reported.

For higher temperatures, the slope of the curve is progressively increasing until finally matching the activation energy corresponding to a purely ionic conducting material $(0.78 \mathrm{eV})$. Thus, although in this temperature range the conduction through the bulk is mixed ionic-electronic, the ionic contribution is the predominant one. Moreover, for these temperatures the conductivity values are slightly higher than the obtained ones after the thermal treatment. As the extra electrons are introduced by reduction of the zirconia, they are linked to the appearance of oxygen vacancies which slightly enhance the ionic conductivity.

Regarding the conductivity through the grain boundary, higher conductivity values and lower activation energy are obtained in the as-sintered 3YTZP-1300 ceramic, in comparison with the oxidized ceramic. The fact that the reduced ceramic shows a lower activation energy points out the existence of a mixed ionic-electronic conduction in this zone, ${ }^{20}$ as the value of the activation energy for electronic conduction is quite lower than that for the ionic one. Thus, the extra electrons present in the reduced sample are also present in the grain boundary. This fact has also been experimentally shown by 
previous authors, ${ }^{6,20,21}$ and is in agreement with the space charge models, ${ }^{26}$ which evidence that extra electrons are expected to be accumulated in the space charge zones in yttria-stabilized zirconia.

To the best of our knowledge, this is the first work devoted to the study of electrical properties of spark plasma sintered $3 \mathrm{~mol} \% \mathrm{Y}_{2} \mathrm{O}_{3}-\mathrm{ZrO}_{2}$ ceramics revealing a significant effect of the introduced electrons on both bulk and grain boundary conductivity in a wide temperature range (from room temperature up to $500{ }^{\circ} \mathrm{C}$ ). Simultaneous increase of both bulk and grain boundary conductivity was previously reported by Guo and Ding ${ }^{20}$ for 8 mol\% $\mathrm{TiO}_{2}-7.36 \mathrm{~mol} \% \mathrm{Y}_{2} \mathrm{O}_{3}$ codoped $\mathrm{ZrO}_{2}$. Although the effect of the extra electrons on the bulk conductivity was not as significant as on the grain boundary conductivity, the increase of the bulk conductivity in the reduced samples was observed even for temperatures higher than $300{ }^{\circ} \mathrm{C}$. Nevertheless, a high density of electrons was introduced in these ceramics by doping with $8 \mathrm{~mol} \% \mathrm{TiO}_{2}$, which would be responsible of these remarkable effects. The only study on spark plasma sintered $\mathrm{Y}_{2} \mathrm{O}_{3}-\mathrm{ZrO}_{2}$ ceramics was published by Lee et al. ${ }^{21}$ for $2.44 \mathrm{~mol} \%$ doped zirconia. They reported enhanced grain boundary conductivity on the reduced ceramics but the bulk conductivity was hardly affected by the introduced electrons. As the sintering conditions were not specified in the study, it is possible that their ceramics are not as strongly reduced as the achieved in the ceramics under study. Moreover, they studied nanocrystalline ceramics (grain size $=23 \mathrm{~nm}$ ) with large grain boundary area to volume ratio, in order to exclusively investigate the grain boundary properties. The submicrometric grain size on the ceramic under study in our work (grain size $=675 \mathrm{~nm}$ ) would allow electrons to be more delocalized in the ceramic and thus influence both bulk and grain boundary conductivity. 


\section{Conclusions}

$3 \mathrm{~mol} \%$ yttria doped zirconia ceramics, with submicrometric grain size and mainly tetragonal phase, were consolidated by spark plasma sintering at two different sintering temperatures. Electrical performance of both as-sintered and thermally treated ceramics was investigated by means of impedance spectroscopy from room temperature up to $500{ }^{\circ} \mathrm{C}$, revealing a remarkably different electrical behaviour in the two ceramics, as a consequence of a different reduction level in them.

When sintering at $1250^{\circ} \mathrm{C}$, the zirconia presents a low reduction level and only the grain boundary conductivity is slightly modified, as the introduced electrons remain mostly localized in deep traps. On the contrary, when sintering at $1300^{\circ} \mathrm{C}$, the introduced extra electrons promoted a strong effect on both the bulk and the grain boundary conductivity, promoting even the existence of conductivity at room temperature. Electronic conduction through the bulk associated to shallower electron traps, C-defects, is observed in this ceramic at temperatures lower than $300{ }^{\circ} \mathrm{C}$, whereas mixed ionic-electronic conduction exists for higher temperatures. The electron accumulation at the space charge zone gives place to mixed ionic-electronic conduction through the grain boundary in a wide temperature range.

\section{Acknowledgements}

The authors acknowledge the financial support provided by the Spanish Ministry of Science and Innovation (MAT2009-11078 and MAT2012-34217) and Junta de Andalucía (P12-FQM-1079). Microscopy studies have been performed in facilities belonging to the CITIUS (Universidad de Sevilla). 


\section{References}

${ }^{1}$ J.D. Solier, I. Cachadiña, A. Domínguez-Rodríguez, Ionic conductivity of $\mathrm{ZrO}_{2}-12$ mol \% $\mathrm{Y}_{2} \mathrm{O}_{3}$ single crystals. Phys. Rev. B 48 (1993) 3704-3712.

2 I. Cachadiña, J.D. Solier, A. Domínguez-Rodríguez, Envejecimiento y propiedades eléctricas de materiales basados en Y-TZP, B. Soc. Esp. Ceram. Vidrio 41, (2002) 437441.

${ }^{3}$ X. Guo, Z. Zhang, Grain size dependent grain boundary defect structure: case of doped zirconia, Acta Mater. 51 (2003) 2539-2547.

${ }^{4}$ U. Anselmi-Tamburini, J.E. Garay, and Z.A. Munir, A. Tacca, F. Maglia, G. Spinolo, Spark plasma sintering and characterization of bulk nanostructured fully stabilized zirconia: Part I. Densification studies, J. Mater. Res. 19 (2004) 3255-3262.

${ }^{5}$ U. Anselmi-Tamburini, J.E. Garay, Z.A. Munir, A. Tacca, F. Maglia, G. Chiodelli, G. Spinolo, Spark plasma sintering and characterization of bulk nanostructured fully stabilized zirconia: Part II. Characterization studies, J. Mater. Res. 19 (2004) 32633269.

${ }^{6}$ X. Guo, R. Waser, Electrical properties of the grain boundaries of oxygen ion conductors: Acceptor-doped zirconia and ceria. Prog. Mater. Sci. 51 (2006) 151-210. ${ }^{7}$ G. Bernard-Granger, C. Guizard, S. Surblé, G. Baldinozzi, A. Addad, Spark plasma sintering of a commercially available granulated zirconia powder-II. Microstructure after sintering and ionic conductivity. Acta Mater. 56 (2008) 4658-4672.

${ }^{8}$ H.J. Park, Y.H. Choa, The grain boundary conduction property of highly dense and nanostructured yttrium-doped zirconia, Electrochem. Solid-State Lett. 13 (2010) K49K52. 
${ }^{9}$ N.H. Perry, T.O. Mason, Grain core and grain boundary electrical/dielectric properties of yttria-doped tetragonal zirconia polycrystal (TZP) nanoceramics. Solid State Ionics $181(2010)$ 276-284.

${ }^{10}$ K. Rajeswari, M. Buchi Suresh, U.S. Hareesh, Y. Srinivasa Rao, D. Das, R. Johnson, Studies on ionic conductivity of stabilized zirconia ceramics (8YSZ) densified through conventional and non-conventional sintering methodologies, Ceramics Int. 37 (2011) $3557-3564$.

${ }^{11}$ K. Rajeswari, M. Buchi Suresh, D. Chakravarty, D. Das, R. Johnson, Effect of nanograin size on the ionic conductivity of spark plasma sintered $8 \mathrm{YSZ}$ electrolyte, Int. J. Hydrogen Energy 37 (2012) 511-517.

${ }^{12}$ B.S. Vasile, E. Andronescu, C. Ghitulica, O.R. Vasile, L. Curechiu, R. Scurtu, E. Vasile, R. Trusca, L. Pall, V. Aldica, Microstructure and electrical properties of zirconia and composite nanostructured ceramics sintered by different methods, Ceramics Int. 39 (2013) 2535-2543.

${ }^{13}$ N.Q. Minh, Ceramic Fuel Cells, J. Am. Ceram. Soc. 76 (1993) 563-588.

${ }^{14}$ W.C. Maskell, Progress in the development of zirconia gas sensors, Solid State Ionics 134 (2000) 43-50.

${ }^{15}$ M. Benammar, W. C. Maskell, Theory and simulation of a miniature zirconia sensor for control of the air-to-fuel ratio in combustion systems, IEEE Sensors Journal 1 (2001) 283-287.

${ }^{16}$ R.M. Ormerod, Solid oxide fuel cells, Chem. Soc. Rev. 32 (2003) 17-28.

${ }^{17}$ M. Levy, J. Fouletier, M. Kleitz, Model for the electrical conductivity of reduced stabilized zirconia, J. Electrochem. Soc. 135 (1988) 1584-1589.

${ }^{18}$ R.I. Merino, V.M. Orera, Correlation between intrinsic electron traps and electrical conductivity in stabilized zirconia, Solid State Ionics 76, (1995) 97-102. 
${ }^{19}$ S. Sano, M. Horiba, T. Endo, A. Tsuzuki, K. Oda, Electric conductivity of solid-state electrochemically reduced yttria partially stabilized zirconia, J. Jpn. Soc. Powder Powder Metal. 51 (2004) 847-851.

${ }^{20}$ X. Guo, Y. Ding, Grain boundary space charge effect in zirconia, J. Electrochem. Soc. 151 (2004) J1-J7.

${ }^{21}$ J.S. Lee, U. Anselmi-Tamburini, Z.A. Munir, S. Kim, Direct evidence of electron accumulation in the grain boundary of yttria-doped nanocrystalline zirconia ceramics, Electrochem. Solid-State Lett. 9 (2006) J34-J36.

${ }^{22}$ D. Eder, R. Kramer, The stoichiometry of hydrogen reduced zirconia and its influence on catalytic activity. Part 1: Volumetric and conductivity studies, Phys. Chem. Chem. Phys. 4 (2002) 795-801.

${ }^{23}$ D. Eder, R. Kramer, Impedance spectroscopy of reduced monoclinic zirconia, Phys. Chem. Chem. Phys. 8 (2006) 4476-4483.

${ }^{24}$ S.A. Cruz SA, R. Poyato, F.L. Cumbrera, J.A. Odriozola, Nanostructured spark plasma sintered Ce-TZP ceramics, J. Am. Ceram. Soc. 95 (2012) 901-906.

${ }^{25}$ M. Li, Z. Feng, G. Xiang, P. Ying, Q. Xin, C. Li, Phase transformation in the surface region of zirconia detected by UV Raman spectroscopy, J. Phys. Chem. B 105, (2001) $8107-8111$.

${ }^{26}$ S. Kim, J. Fleig, J. Maier, Space charge conduction: Simple analytical solutions for ionic and mixed conductors and application to nanocrystalline ceria, Phys. Chem. Chem. Phys. 5 (2003) 2268-2273. 


\section{Figure Captions}

Figure 1: HRSEM micrographs of thermally etched polished surfaces and grain size distribution plots of the ceramics sintered at (a) $1300{ }^{\circ} \mathrm{C}$ and (b) $1250{ }^{\circ} \mathrm{C}$.

Figure 2: Raman spectra acquired on the as-sintered and thermally treated ceramics sintered at (a) $1300{ }^{\circ} \mathrm{C}$ and (b) $1250{ }^{\circ} \mathrm{C}$.

Figure 3: (a) Impedance spectra and (b) Z" spectroscopic plots, acquired from room temperature up to $210^{\circ} \mathrm{C}$ in the as-sintered $3 \mathrm{YTZP}-1300$ ceramic.

Figure 4: Impedance plots measured at $\mathrm{T}=300{ }^{\circ} \mathrm{C}$ in the as-sintered and thermally treated 3YTZP ceramics sintered at (a) $1300{ }^{\circ} \mathrm{C}$ and (b) $1250{ }^{\circ} \mathrm{C}$. Solid lines represent the fitting results. The inset in (a) shows the equivalent circuit used to fit the impedance data.

Figure 5: Arrhenius plots of bulk (full symbols) and grain boundaries (open symbols) conductivities of as-sintered and thermally treated 3YTZP ceramic sintered at $1250{ }^{\circ} \mathrm{C}$.

Figure 6: Arrhenius plots of bulk (full symbols) and grain boundaries (open symbols) conductivities of as-sintered and thermally treated 3YTZP ceramic sintered at $1300{ }^{\circ} \mathrm{C}$. 

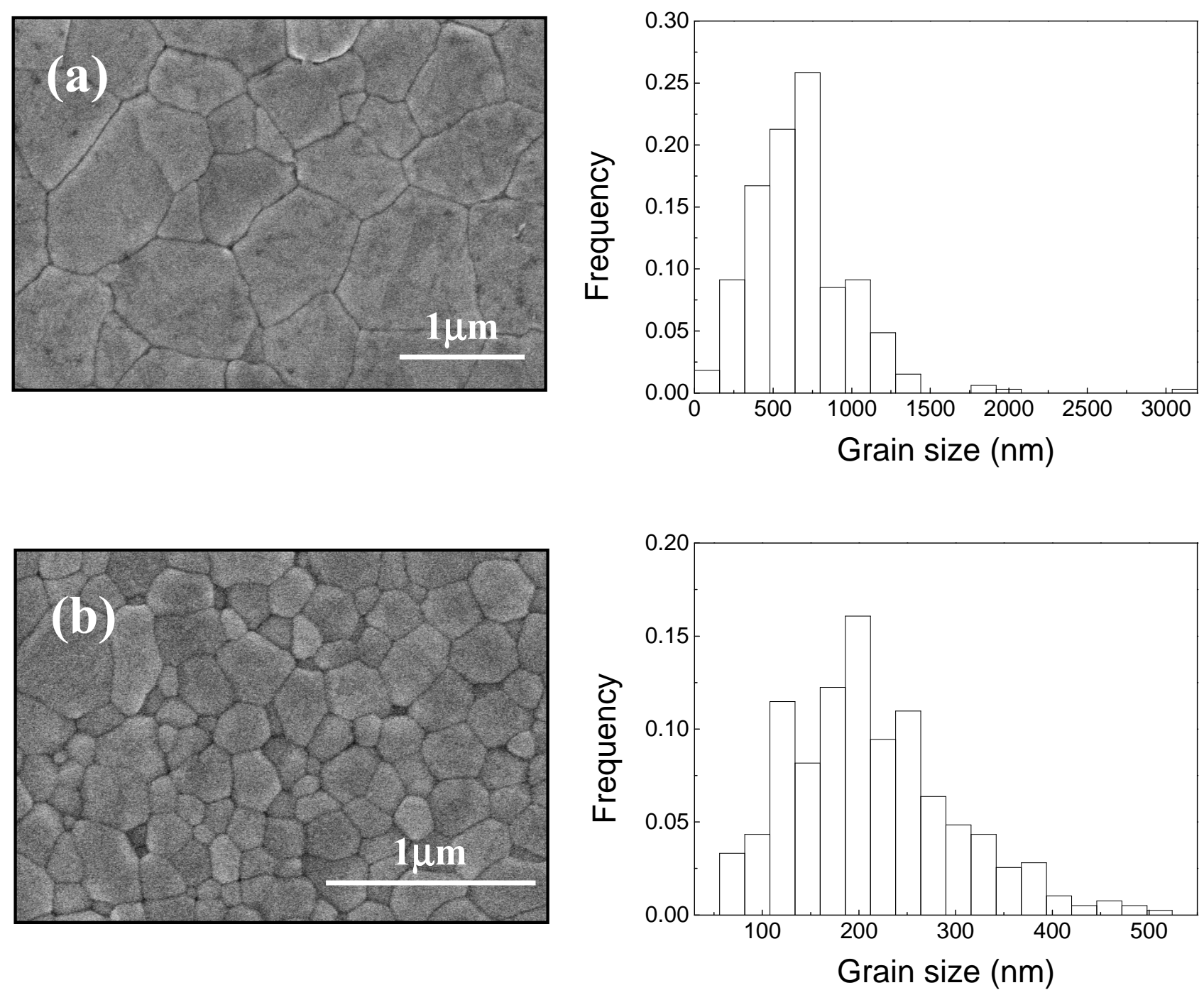

Figure 1 


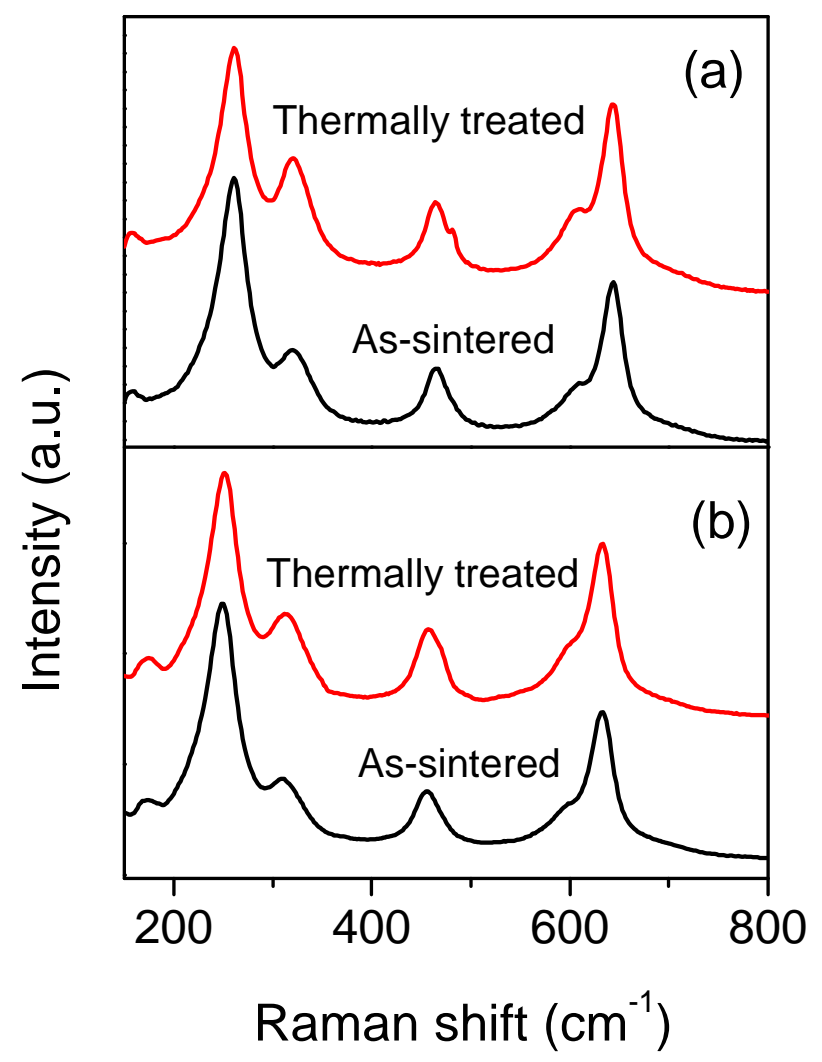

Figure 2 

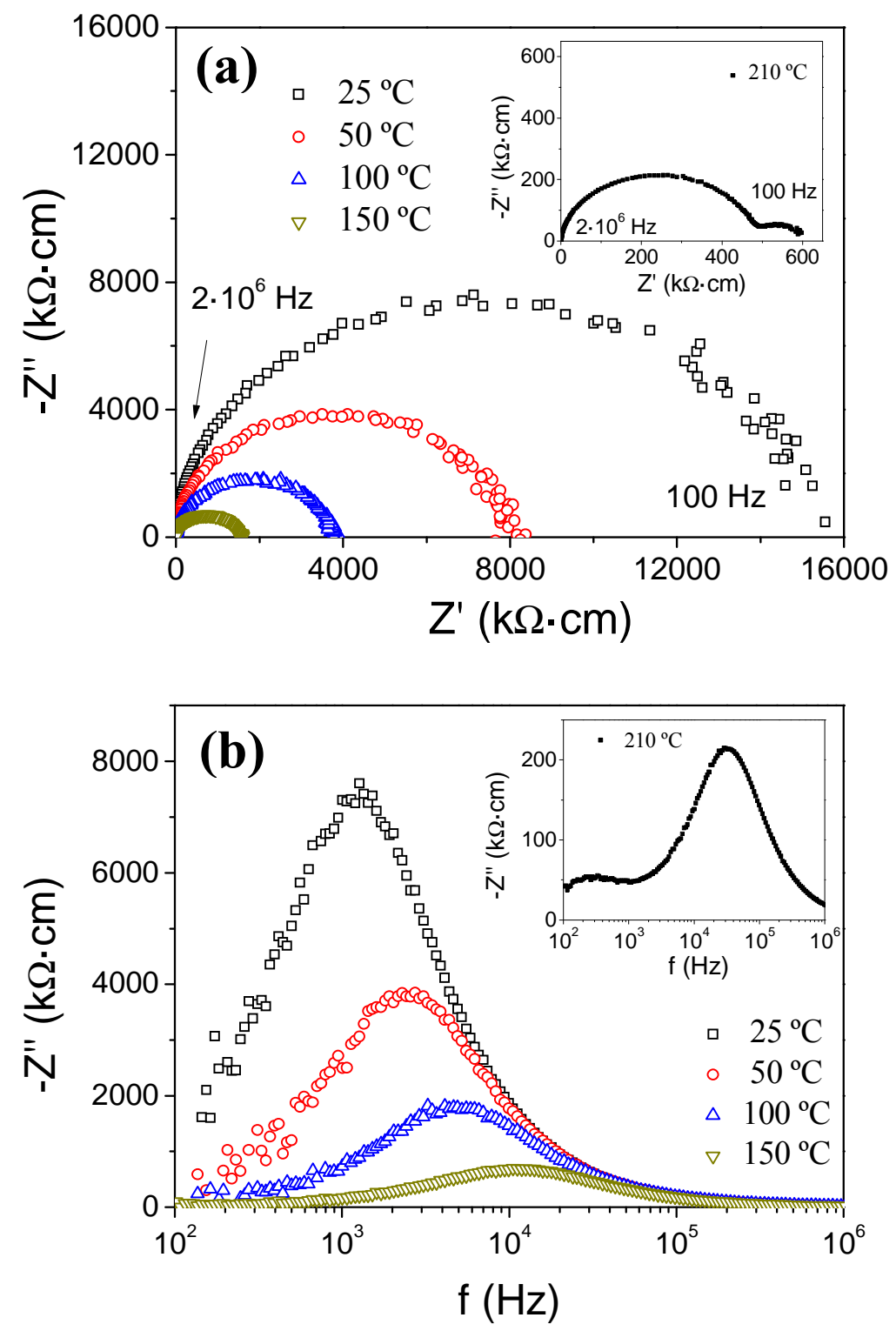

Figure 3 

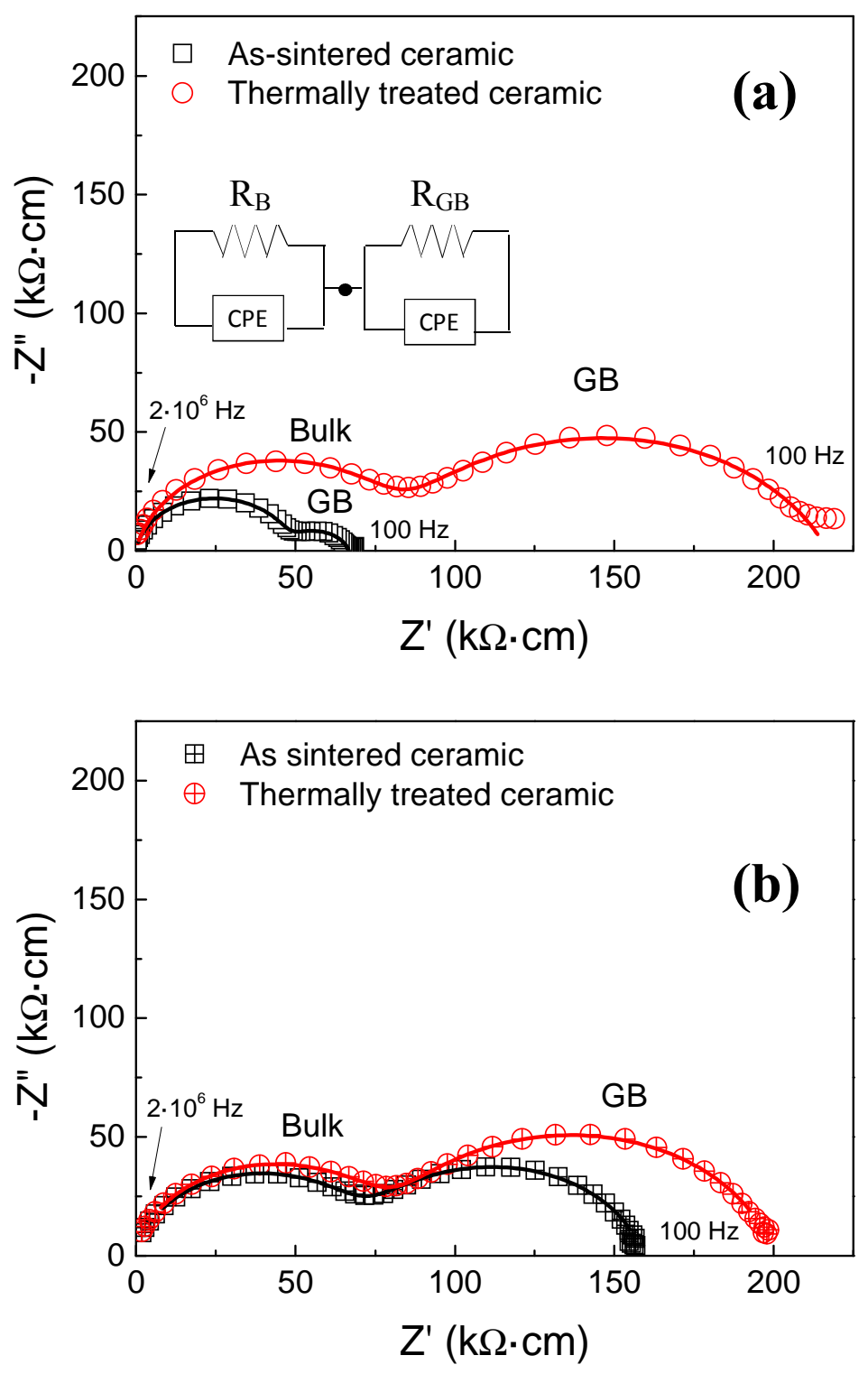

Figure 4 


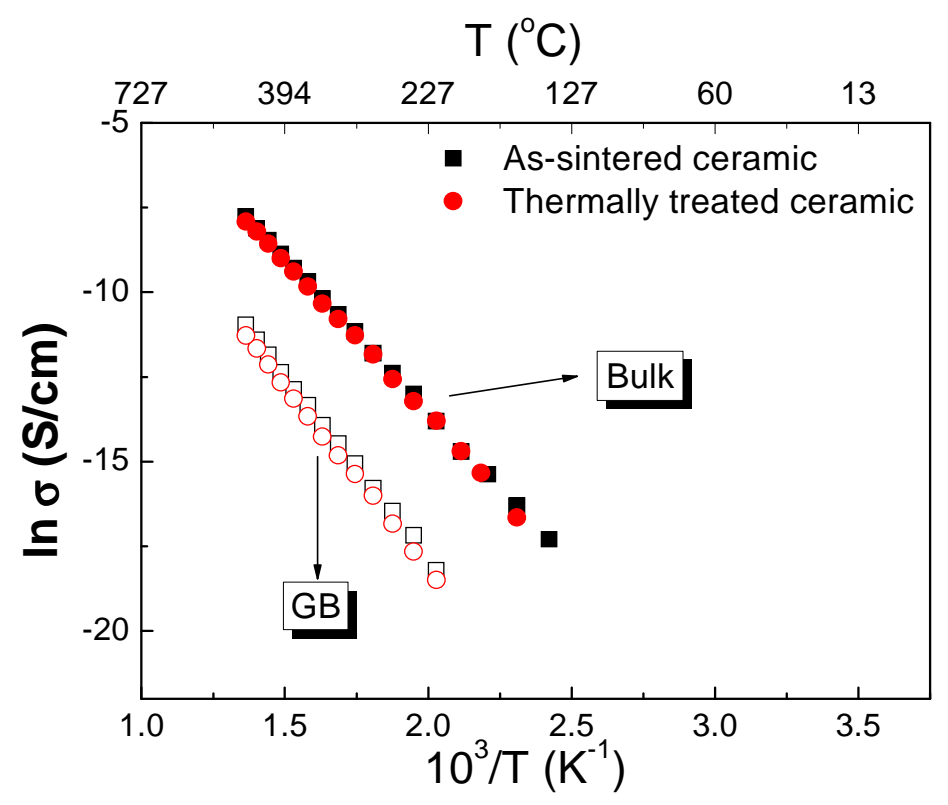

Figure 5 


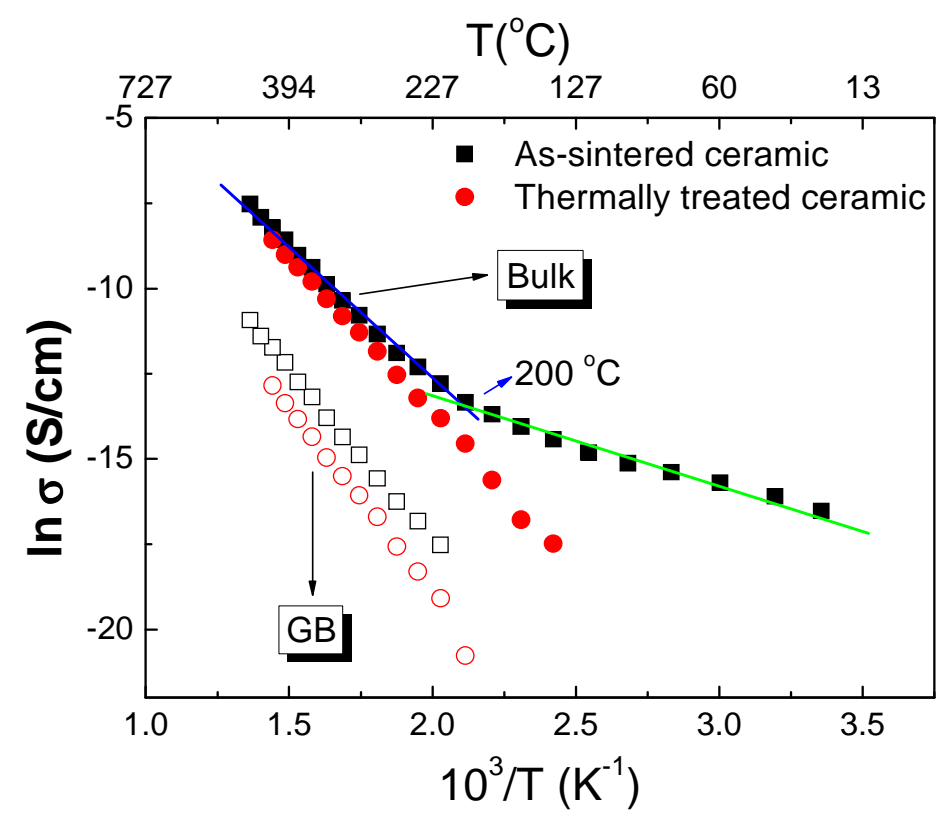

Figure 6 
Table 1: Relative density and morphological parameters of the 3YTZP ceramics.

\begin{tabular}{ccccc}
\hline Ceramic & $\rho_{\mathbf{r}}$ & $\langle\mathbf{d}\rangle$ & $\boldsymbol{\sigma}_{\mathbf{d}}$ & $\mathbf{f}$ \\
& $\mathbf{( \% )}$ & $\mathbf{( n m )}$ & $\mathbf{( n m )}$ & \\
\hline 3YTZP-1250 & 97 & 215 & 85 & 0.75 \\
3 YTZP-1300 & 100 & 675 & 327 & 0.72 \\
\hline
\end{tabular}


Table 2: Activation energies for the bulk and grain boundary conductivity in the assintered and thermally treated 3 YTZP ceramics sintered at 1250 and $1300{ }^{\circ} \mathrm{C}$. Ea $a_{1 \text { Bulk }}$ corresponds to activation energy for $\mathrm{T}<200{ }^{\circ} \mathrm{C}, \mathrm{Ea}_{2 \mathrm{Bulk}}$ corresponds to activation energy for $\mathrm{T}>300^{\circ} \mathrm{C}$.

\begin{tabular}{|c|c|c|c|c|}
\hline \multicolumn{2}{|c|}{ Ceramic } & $\begin{array}{c}\text { Ea 1Bulk } \\
(\mathbf{e V})\end{array}$ & $\begin{array}{c}\text { Ea2Bulk } \\
(\mathbf{e V})\end{array}$ & $\begin{array}{r}\mathbf{E} \mathbf{a}_{\mathrm{GB}} \\
(\mathrm{eV})\end{array}$ \\
\hline \multirow{2}{*}{3 YTZP-1250 } & As-sintered & & 0.78 & 0.92 \\
\hline & Thermally treated & & 0.79 & 0.93 \\
\hline \multirow[t]{2}{*}{3 YTZP-1300 } & As-sintered & 0.20 & 0.78 & 0.87 \\
\hline & Thermally treated & & 0.79 & 0.92 \\
\hline
\end{tabular}

